\title{
Frequency of Hepatitis A \& E Infections in Adult Patients of Acute Hepatitis
}

\section{Rukhsana Gulzar, ${ }^{1}$ Rehma Dar, ${ }^{2}$ Qurat ul Ain, ${ }^{3}$ Humair Ahmad, ${ }^{4}$ Syed Saqib Ali Shah, ${ }^{5}$ Hira Sajjad $^{6}$}

\begin{abstract}
Objective: To study the frequency of Hepatitis A Virus and Hepatitis E Virus infections in adult patients of acute hepatitis in a Tertiary Care Hospital in Lahore.

Methods: All samples received from medical units (indoor and outdoor) of Mayo hospital Lahore from 26 Feb.2019 to 26.Sept.2019, for Hepatitis A \& E IgM antibody testing by ELISA were included in the study. The results and other relevant information were recorded on proforma.

Results: Out of 690 study subjects, $62 \%$ were male and $38 \%$ were female. The mean age \pm SD was $33.8 \pm$ 7.4years. The percentage of HAV or HEV infected cases was $59 \%$, and $41 \%$ were not infected with HAV or HEV. The frequency and percentage of Hepatitis A Virus was 62(15\%), whereas the frequency and percentage of HEV was $327(80 \%)$ and that of co-infection with HAV and HEV was 21(5\%). The mean \pm SD age of Hepatitis AVirus was 35.2 \pm 5.0 ,whereas the mean $\pm \mathrm{SD}$ age of Hepatitis E Virus and co-infection with Hepatitis A and Hepatitis E Virus were $31.45 \pm 2.3$ and $22.6 \pm 6.3$ years, respectively.

Conclusion: Hepatitis E Virus is the commonest cause of acute hepatitis in our study,followed by hepatitis A Virus and coinfection of HAV and HEV.

Key words: Frequency, Hepatitis A infection, Hepatitis E infection, Co- infection Hepatitis A \& Hepatitis E.
\end{abstract}

\section{Introduction}

A cute viral hepatitis is a grave public health problem. Presently, six hepatotropic viruses, classified as hepatitis A, B, C, D, E and G are the prime cause of its pathogenicity. ${ }^{1-3}$

The prevalence of hepatitis varies globally and also within countries. Hepatitis A virus (HAV) and hepatitis E virus (HEV) are transmitted via fecal-oral route and infection usually resolves after causing acute hepatitis. Exposure to contaminated blood and its products and body fluids are responsible for the transmission of Hepatitis B, hepatitis C and hepatitis D viruses and the

\begin{tabular}{|c|c|}
\hline 1. Rukhsana Gulzar & 2. Rehma Dar \\
\hline 3. Qurat-ul-Ain & 4. Humair Ahmad \\
\hline 5. Syed Saqib Ali Shah & 6. Hira Sajjad \\
\hline \multicolumn{2}{|c|}{ 1. Pak Red Crescent Medical \& Dental College, Lahore } \\
\hline \multicolumn{2}{|c|}{ 2-4 King Edward Medical University, Lahore. } \\
\hline \multicolumn{2}{|c|}{ 5. Services Institute of Medical Sciences Lahore } \\
\hline \multicolumn{2}{|c|}{ 6. Rahber Medical and Dental College Lahore } \\
\hline \multicolumn{2}{|l|}{ Correspondence: } \\
\hline \multicolumn{2}{|l|}{ Rukhsana Gulzar, } \\
\hline \multicolumn{2}{|c|}{ Assistant Professor Chemical Pathology } \\
\hline \multicolumn{2}{|c|}{ Pak Red Crescent Medical and Dental College, Lahore } \\
\hline \multicolumn{2}{|c|}{ Email: rukhsanagulzarsajjad@gmail.com } \\
\hline Submission Date: & $19-08-2020$ \\
\hline 1st Revision Date: & 02-10-2020 \\
\hline Acceptance Date: & $28-10-2020$ \\
\hline
\end{tabular}

incidence of chronic hepatitis is very high. HAV-HEV co-infection is also common. According to WHO, every year 1.4 million new cases of HAV and 20 million cases of HEV are reported around the world, with 100,000 deaths per year due to acute HAV and 60,000 deaths due to HEV infection. ${ }^{2,4-8}$

Most cases of the acute hepatitis due to A and $\mathrm{E}$ infections cannot be distinguished from other causes of acute hepatitis on clinical grounds. For the appropriate diagnosis of acute viral hepatitis, deranged liver function tests (LFTs) and positive serological markers for the suspected virus are required. In acute hepatitis A infection, anti-HAV IgM antibodies rise immediately after the onset of the disease, and antibody titres declines to zero in 3-6 months, while anti-HAV IgG antibodies appear within 2-3 months after the onset of acute infection and persist longer. $\mathrm{IgG}$ antibodies provide long term protective immunity, whereas IgM antibodies against HAV and HEV detected by ELISA technique are used to diagnose acute infection. ${ }^{9}$

The greatest risk for HAV and HEV infection in developing countries is poor hygiene and sanitation. Contamination of water resources is the main cause of 
spread. ${ }^{5}$ In Pakistan 3.5 to $4 \%$ cases of acute hepatitis in adults and 50 to $60 \%$ in children are caused by Hepatitis A virus. Majority children are exposed to this virus during their early age and remain immune afterwards. ${ }^{2,47-12}$ HAV was previously considered an acute self-limiting infection in children, ${ }^{5,9,14}$ but Hamid et al conducted a study on 233 cases of chronic liver disease and found that $97.8 \%$ of his study population was exposed to HAV. ${ }^{14}$ In another study conducted on a series of 2,735 confirmed cases of acute HAV, from a Tertiary Care Hospital in Pakistan, it was observed that 232 children required hospitalization and out of these $36.7 \%$ died. ${ }^{5}$

In developing countries including Pakistan, hepatitis E virus causes outbreaks as well as sporadic cases $(7,13)$. Unlike HAV, HEV causes acute hepatitis in 20 to $22 \%$ of adults and $2.4 \%$ of children. ${ }^{14}$ Once infected the individuals remain immune for 8-10 years, but can be reinfected later. It is a self limiting disease, but in pregnancy, the outcome can be fatal, and in the last trimester mortality rate as high as $16-33 \%$ has been reported. ${ }^{2,5,18}$

Studies report a benign course of HAV and HEV coinfection, but fulminant liver failure may occur in pregnant patients. ${ }^{16}$ When more than one viral infection occurs, patients are usually older males, they have risk factors for contracting the disease, and the disease outcome is often worse. ${ }^{17}$

Preventive measures like better sanitary conditions, availability of clean water, education of public regarding the spread of the disease and its prevention can be helpful in reducing the disease burden.

\section{Methods}

It was a descriptive study conducted at Central Diagnostic Laboratory (CDL), Mayo Hospital/ King Edward Medical University, Lahore, after approval of Institutional Review Board. All samples sent to CDL for anti HAV \& HEV IgM testing from medical units (indoor and outdoor)of Mayo hospital, Lahore, were included in the study. The relevant information of patients like age, gender were noted on proforma. Improperly labeled and inadequate samples were excluded from the study.

The samples were collected in yellow top vaccutainer, centrifuged and serum was separated and stored in refrigerator at $-20^{\circ} \mathrm{C}$ to run in batches. After calibration, ELISA was performed using AutoBio and Diapro kits for anti HAV \& HEV IgM respectively on Dia 710 ELISA microplate reader. The results were marked as positive or negative and recorded on proforma.

All collected data was entered and analyzed by using Statistical package for social sciences (SPSS version 20). Quantitative variable like age was presented as mean \pm SD. Qualitative variables like gender, infected and non-infected, positive results for Hepatitis A, E \& co-infection were presented as frequency and percentage.

\section{Results}

The total numbers of patients $(\mathrm{N})$ included in the study with the suspicion of acute hepatitis were 690 . The mean \pm SD age of patients was $33.8 \pm 7.4$ years. The male: female was $62: 38 ; 428$ males and 262 females.

Figure 1: Frequency\& Percentage of Infected and Non-Infected Cases $(N=690)$.

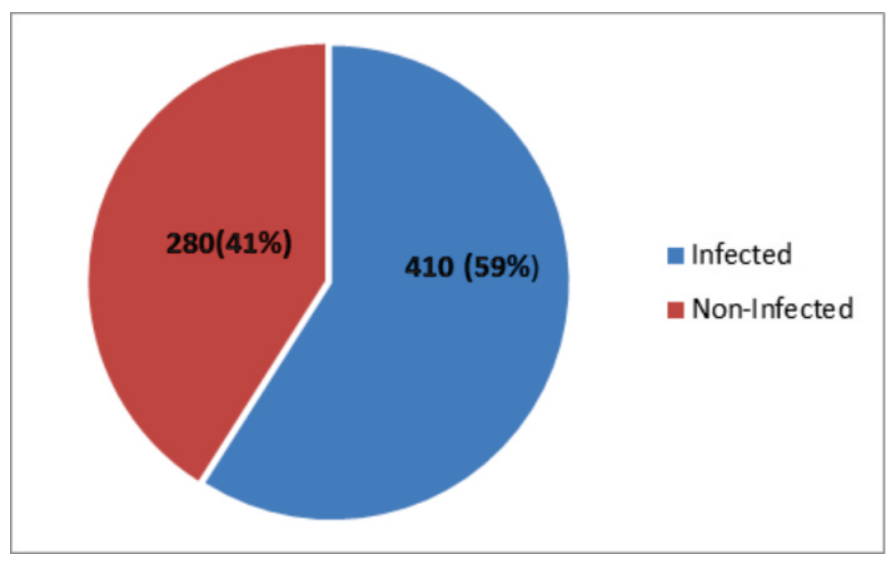

Figure 2: Frequency\& Percentage of Hepatitis $A, E$ and Co-Infection $A \& E(N=410)$.

Figure 3: Percentage of male and female in $H A V$, $H E V$ and co-infection $A \& E$.

Out of $62 \mathrm{HAV}$ infected patients, there were 35 males 


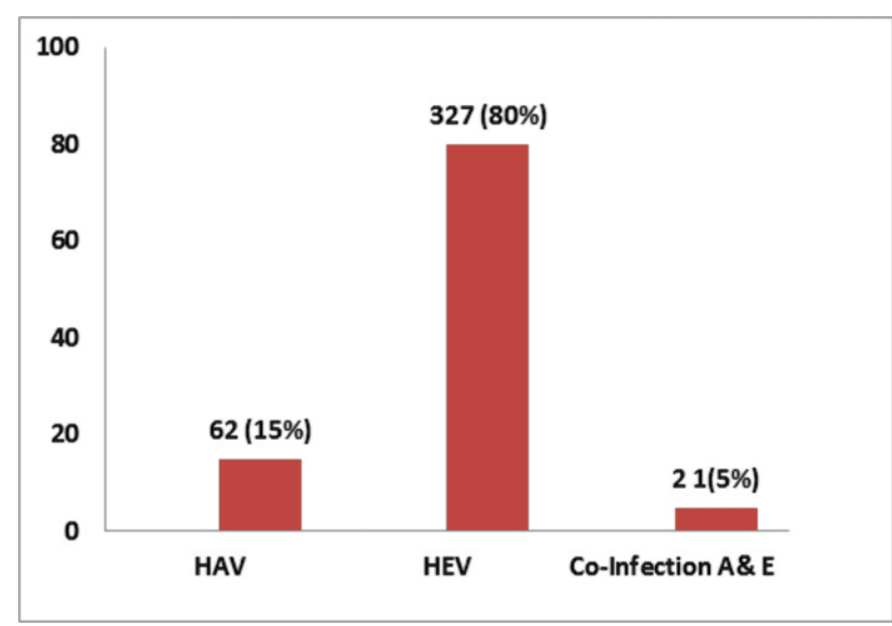

and 27 females. There were 201 males and 126 females out of $327 \mathrm{HEV}$ infected and 14 males and

Table 1: Age of Patients with HAV, HEV \& Co-infection $A \& E$.

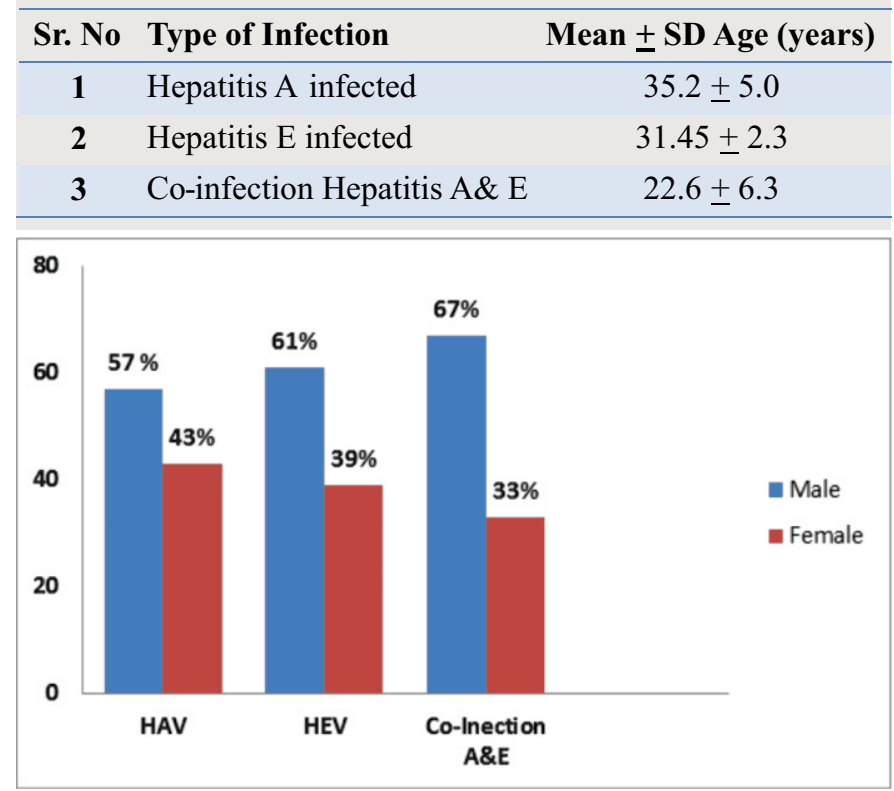

and 7 females among 21 patients co- infected with A\&E.

\section{Discussion}

Pakistan has a high disease burden of hepatitis A to E, with maximum morbidity in hepatitis $A$ and $E$ and maximum mortality in hepatitis $\mathrm{B}, \mathrm{C}$ and $\mathrm{D}{ }^{2}{ }^{2}$

Since acute viral hepatitis due to HAV and/or HEV is common, it is a challenge for the government and healthcare providers. This study was conducted at the time when there were increasing number of cases of acute hepatitis in Lahore. In our study, 690 patients with the suspicion of acute viral hepatitis were included. Among these patients, $410(59 \%)$ were infected with Hepatitis A \& E and 280(41\%) were not infected with HAV or HEV(Fig.1).
Among the infected patients, 62(15\%) were infected by HAV (Figure 2). Despite Pakistan being high endemic zone for HAV, its frequency is less than HEV infection in our study. ${ }^{9,10}$ This difference can be attributed to the age of study population which was $33.8 \pm 7.4$ years (Table.1). Our study population comprised of adults and HAV infection is more common in children and since it gives lifelong immunity, it is possible that many adults might have acquired immunity as a result of previous infection. Previously it was considered that by the age of 14 years almost $100 \%$ of children have been exposed to hepatitis About recent studies show that there is a change in the trend of occurrence of hepatitis $A$, and now all age groups are affected. ${ }^{14}$ This change in trend can be due to improvement in hygienic conditions or better understanding by the parents to maintain a good standard of hygiene, and children are exposed to contaminated food as they grow older. ${ }^{8,15}$

The frequency of HEV infection was 327(80\%) (Fig.2). It is comparable to studies conducted in Pakistan and other countries where HEV was the major cause of outbreaks. ${ }^{1,13,14} \mathrm{HEV}$ affects mainly young and middle age individuals and this trend is seen in our study also in which the mean age of patients with HEV infection was $31.45+2.3$. This is similar to study by Bosan A et al in which Hepatitis E mainly affects the adult population. ${ }^{2}$ Like HAV, HEV also produces a mild self-limiting disease in majority of the patients, but in a few cases, it may lead to fulminant hepatic failure. ${ }^{1,15}$ In pregnant women, the mortality rate is significant, ranging between 20 and $29.3 \%{ }^{14,19,22}$

In the present study, 21(5\%) of the infected individuals were co-infected with HAV \& HEV(Fig.2). Coinfection with HAV-HEV is a not uncommon. ${ }^{20}$ The infection is usually self-limiting but atypical manifestations such as fulminant hepatic failure have also been reported. ${ }^{15}$

In our study, the frequency and percentage of male: female HEV infected patients, were 201(61\%) and $126(39 \%)$ respectively (Fig.3). The frequency and percentage of male: female HAV infected patients were $35(57 \%$ ) and $27(43 \%)$ respectively (Fig.3). Both HAV and HEV infections were more common in males, probably because of outside eating habits. This is comparable with a survey performed in 2009, by 
the Pakistan Field Epidemiology and Laboratory Training Program (FELTP), in collaboration with CDC's Division of Viral Hepatitis and Ministry of Health observing that the incidence of HAV in males was $69.5 \%$ and that of HEV was $72.4 \%{ }^{14}$

Since there is increasing risk of acute hepatitis in the community, provision of safe water and educating public about the modes of spread is the need of the day. Early vaccination of children for HAV can reduce the morbidity and mortality. Since no vaccine is commercially available for HEV infection, preventive measures need to be propagated. Policies should be formulated to provide hygienic basic facilities and better sanitary conditions to our population.

\section{Conclusion}

1. In our study, HEV is the most common cause of acute hepatitis.It is followed by HAV and coinfection with HAV and HEV.

2. HAV, HEV and co-infection with HAV and HEV is more common in adult males less than 40 years old.

\section{Author's Contribution}

RG: Conceived, designed and writing of manuscript

RD: StatisticalAnalysis

QA, SAS: Data Collection

HA: Data Collection and Statistical Analysis

H.S: Writing of manuscript

\section{References}

1. Siddique T, Farzand S, Waheed SS. Frequency of Hepatitis E (HEV) patients in Medical Unit-I of a tertiary care teaching hospital Lahore.PJMHS.2012 Apr-Jun;6(2)502-503.

2. Bosan A, Qureshi H, Bile KM, Ahmad I, Hafiz R. A review of hepatitis viral infections in Pakistan. JPMA-Journal of the Pakistan Medical Association. 2010 Dec 1;60(12):1045-1058.

3. Abro AH, Abdou AM, Saleh AA, Ustadi AM, Hussaini HS. Hepatitis E: a common cause of acute viral hepatitis. J Pak Med Assoc. 2009 Feb;59(2):92-4

4. Organization WHO. Global policy report on the prevention and control of viral hepatitis in WHO Member States. 2013.

5. Butt AS. Epidemiology of viral hepatitis and liver diseases in Pakistan. Euroasian journal of hepatogastroenterology. $2015 \mathrm{Jan} ; 5(1): 43-48$.

6. Sharma AK, Dutta U, Sinha SK, Kochhar R. Upsurge in vaccine preventable hepatitis A virus infection in adult patients from a tertiary Care Hospital of North India.International Journal of infectious diseases. 2016Apr 1;45(1) :457.

7. Ramachandran J, Eapen C, Kang G, Abraham P, Hubert DD, Kurian G, et al. Hepatitis E superinfection produces severe decompensation in patients with chronic liver disease. Journal of gastroenterology and hepatology. 2004;19(2):134-8..

8. Agrawal A, Singh S, Kolhapure S, Hoet B, Arankalle V, Mitra M. Increasing Burden of Hepatitis A in Adolescents and Adults and the Need for Long-Term Protection: A

9. Review from the Indian Subcontinent. Infectious diseases and therapy. 2019 Nov 2:1-5.

10. Patterson J, Abdullahi L, Hussey GD, Muloiwa R, Kagina B M. A Systematic review of the epidemiology of hepatitis A in Africa. BMC infectious diseases. 2019 Dec 1;19(1):651.

11. World Health Organization. WHO position paper on hepatitis A vaccines-June 2012. Weekly Epidemiological Record= Relevé épidémiologique hebdomadaire. 2012;87(28-29):261-76.

12. Butt N, Khan M A, Haleem F. Acute viral hepatitis: Simultaneous infection from hepatitis A, B and E viruses. J Coll Physicians Surg Pak 2019; 29 (Supplement 2):103-105.

13. Banks M, Bendall R, Grierson S, Heath G, Mitchell J, Dalton H. Human and porcine hepatitis E virus strains, United Kingdom. Emerging infectious diseases. 2004 May;10(5):953.

14. Ghabrah TM, Tsarev S, Yarbough PO, Emerson SU, Strickland GT, Purcell RH. Comparison of tests for antibody to hepatitis E virus. Journal of medical virology. 1998 Jun;55(2):134-7.

15. Butt AS, Sharif F. Viral hepatitis in Pakistan: past, present, and future. Euroasian journal of hepatogastroenterology. 2016 Jan;6(1):70-81.

16. Jafri W, Yakoob J, Abid S, Awan S, Siddiqui S, Jafri F, Hamid S, Nizami SQ. Seroprevalence of hepatitis E and Helicobacter pylori in a low socioeconomic area of a metropolitan city in a developing country. British journal of biomedical science. 2013 Jan 1;70(1):2730.

17. Jain J, Jain M. Atypical manifestations of viral hepatitis A and E. Tropical doctor. 2013;43(1):17-8.

18. De Paschale M, Ceriani C, Romanò L, Cerulli T, Cagnin D, Cavallari S, Ndayake J, Zaongo D, Diombo K, Priuli G, Viganò P. Epidemiology of hepatitis $\mathrm{E}$ virus infection during pregnancy in Benin. Tropical Medicine \& International Health. 2016 
Jan;21(1):108-13.

19. Baatarkhuu O, Lee HW, George J, Munkh-Orshikh D, Enkhtuvshin B, Ariunaa S, Eslam M, Ahn SH, Han $\mathrm{KH}, \mathrm{Kim} \mathrm{DY}$. Acute hepatitis A, B and C but not D is still prevalent in Mongolia: a time trend analysis. Clinical and molecular hepatology. 2017 Jun; 23(2): 147.

20. Yasmeen T, Hashmi HA, Taj A. Fetomaternal outcome with hepatitis e in pregnancy. J Coll Physicians Surg Pak. 2013 Oct 1;23(10):711-4.
21. Jain P, Prakash S, Gupta S, Singh KP, Shrivastava S, Singh DD, Singh J, Jain A. Prevalence of hepatitis A virus, hepatitis $B$ virus, hepatitis $C$ virus, hepatitis D virus and hepatitis $\mathrm{E}$ virus as causes of acute viral hepatitis in North India: A hospital based study. Indian journal of medical microbiology. $2013 \mathrm{Jul}$ 1;31(3):261.

22. Sultana R, Humayun S. Fetomaternal outcome in acute hepatitis E. J Coll Physicians Surg Pak. 2014; 24(2):127-30 